\title{
Segregation and Integration: Changes in the Social Diversity of Toronto's Upper Class
} Suburbs, 1870s-1920s

Alicja Grzadkowska

Third Year Paper

Chicago Style Citation

At the beginning of its development, suburban housing in and around Toronto was viewed as a solution to the poor living standards found in Toronto's slums, thereby attracting primarily middle and upper class families. ${ }^{1}$ It is important to note that many early suburbs were also appealing for marginalized groups of immigrants and the working class. ${ }^{2}$ However, the current essay will primarily explore the construction and development of upper class-dominated regions, and use the term "suburb" in reference to prestigious districts located near or in the city, such as Forest Hill, the Annex, and Parkdale, which primarily comprised of middle and upper class housing in the late 1800s. ${ }^{3}$ By the turn of the century, these suburban neighbourhoods were undergoing significant changes associated with urban development. While some suburbs, such as Parkdale and the Annex, were modeled with the intent of housing wealthy and middle-class people, a movement of blue-collar workers and non-British immigrants to the "morally distinct" neighbourhoods of the city began in the 1890s and continued throughout the $1900 \mathrm{~s} .{ }^{4}$ The relocation was influenced by the expansion of industries in Toronto, the housing boom that took place between 1906 and 1913, and the growing affordability of land located outside of the city's core.

This essay will argue that industrial development and housing expansion influenced the construction of class relations in Toronto's suburbs, specifically by creating social divisions based on residents' inner city or industry-based employment, their segregated geographical

\footnotetext{
${ }^{1}$ Carolyn Whitzman, Suburb, Slum, Urban Village: Transformations in Toronto's Parkdale Neighbourhood, 1875-2002 (Vancouver: UBC Press, 2009), 31.

${ }^{2}$ Larry McCann, "Suburbs of Desire: The Suburban Landscape of Canadian Cities, c. 1900-1950," in Changing Suburbs: Foundation, Form and Function, ed. Richard Harris and Peter J. Larkham (New York: Routledge, 1999), 114.

${ }^{3}$ Richard Harris, Creeping Conformity: How Canada Became Suburban, 1900-1960 (Toronto: University of Toronto Press, 2004), 20.

${ }^{4}$ Whitzman, Suburb, Slum, Urban Village, 63.
} 
localization on neighbourhood streets, and class-specific use of public transportation as a means of travelling in and out of Toronto. These divisions contributed to rising tensions as urbanization pushed people to the neighbourhoods located on the fringes of the city, thereby forcing suburban residents to interact with new, working class neighbours. In many regions, the diversification of classes resulted in a corruption of the ideal image of the suburb as imagined in the 1870s and 1880s, and promoted class integration, which persisted until the 1930s when suburbs became increasingly middle-class. ${ }^{5}$

\section{Constructing Toronto's Pristine Suburbs}

Suburbs existing around Toronto as well those located in the city during the latter half of the nineteenth century can attribute their development to Toronto's urban sprawl in the late1800s, which resulted from the city's rapid economic growth. Between 1870 and 1901, Toronto's economy experienced radical development through industrialization, which caused an urban reorganization of the city as its economic capacity increased and industrial areas began growing. ${ }^{6}$ Parallel to Toronto's industrial expansion was an increase in the city's population, which grew from 56,000 in 1871 to 86,000 in 1881, and while Toronto's racial profile remained primarily British during this time and into the 1950s, the city also became a destination point for migrants from Europe. ${ }^{7}$ The rise in the city's population was accompanied by an increase in housing, mainly located in the city's downtown core where migrants settled. Large-scale Irish immigration in the 1840 s and Jewish immigration in the 1890s diluted the British population, and the groups occupied run-down homes in the area of Toronto known as the Ward. ${ }^{8}$ In contrast, many British families often found housing on the outskirts of the city in more upscale

\footnotetext{
${ }^{5}$ Richard Harris, “A Working-Class Suburb for Immigrants, Toronto 1909-1913," Geographical Review 31, no. 3 (Jul., 1991): 321.

${ }^{6}$ Peter G. Goheen, Victorian Toronto: 1850 to 1900: Pattern and Process of Growth (Chicago: University of Chicago Printing Department, 1973), 64.

${ }^{7}$ Goheen, Victorian Toronto, 64-65; Marc Choko and Richard Harris, "The Local Culture of Property: A Comparative History of Housing Tenure in Montreal and Toronto," Annals of the Association of American Geographers 80, no. 1 (Mar., 1990): 88.

${ }^{8}$ Richard Dennis, "Property and Propriety: Jewish Landlords in Early Twentieth-Century Toronto," Transactions of the Institute of British Geographers 22, no. 3 (1997): 380, 378; Goheen, Victorian Toronto, 75.
} 
suburbs where they were distanced from the slums located in the heart of the city, which were conceptualized by the more affluent classes as unclean and dangerous areas. ${ }^{9}$

These British-dominated suburbs were spaces where families could establish comfortable and safe lives, and their popularity indicated the desire for separation between the immigrant working class and upper classes. As a result, the neighbourhoods became synonymous with upright moral values and the maintenance of a 'healthful' lifestyle away from the polluted metropolis. Parkdale is an example of a suburb that was initially intended to protect its residents from the 'immoral' qualities of the city while providing affordable housing. On July 1, 1878, in the midst of annexation debates concerning municipalities surrounding Toronto, an anonymous resident of the Parkdale suburb spoke about his reasons for moving to the up-and-coming housing development in the Globe. The resident acknowledged that "he built in Parkdale simply to avoid the city taxes, while availing himself of city conveniences," demonstrating the economic benefits of living on inexpensive land located outside of the city's perimeters in suburbs like Parkdale, as well as the distance that the neighbourhood maintained from the city. ${ }^{10}$

The report went on to argue that the movement of people out of Toronto was "natural" as the public did not "wish to see houses huddled together in a way that is injurious to both health and comfort," referring to the conditions of inner-city slums. ${ }^{11}$ Accordingly, the idea of the pristine suburb was a reactionary development to the substandard and overcrowded conditions in Toronto's shantytowns. Homes in Parkdale were by comparison more spacious and housed single families, and issues of public health, which plagued inner-city populations until the 1910s, did not affect the neighbourhood. ${ }^{12}$ Parkdale, like other suburbs developing in North America during the time period, was thus depicted as a solution to the urban problem of the slum. ${ }^{13}$

The anonymous resident in the Globe article likewise stated that he and his neighbours belonged to the business people "seen everyday on King-street," emphasizing Parkdale's status as a predominantly middle-class suburb that offered an escape from the lower class housing located in downtown Toronto. ${ }^{14}$ In Carolyn Whitzman's study of the municipality, the historian argues that in the 1870s, Parkdale was a "new kind of space" where middle-class values were

\footnotetext{
${ }^{9}$ Lawrence Solomon, Toronto's Sprawls: A History (Toronto: University of Toronto Press, 2007), 19.

10 "Suburean Corporations," Globe, July 1, 1878, 2.

${ }^{11}$ Ibid.

${ }^{12}$ Harris, Creeping Conformity, 52.

${ }^{13}$ Whitzman, Suburb, Slum, Urban Village, 31.

14 "Suburean Corporations."
} 
upheld and families could thrive, since Parkdale was associated with the "extension of the safe domestic sphere."15 The neighbourhood's residents took pride in the remote 'floral' suburb, a nickname that Parkdale assumed early on in its development. On a civic holiday in 1879, a celebration was organized in the neighbourhood, and included a picnic where refreshments were served and the neighbourhood's children could play games for the afternoon. ${ }^{16}$ The focus on the health of its residents through organized social interactions, and the maintenance of the natural landscape that allowed for outdoor events, emphasized the benefits of the neighbourhood and helped to construct its image as an ideal middle-class region. It was a place of "innocent amusements and moral advancement" ${ }^{\prime 17}$ that existed in stark contrast to the polluted expanding city. Physically, Parkdale was also known for its "natural beauty" as a picturesque municipality surrounded by greenery, additionally revealing the prominent differences between Toronto's industrial downtown and the serene municipality. ${ }^{18}$

The Annex was similarly recognized as a prosperous and pleasant neighbourhood, particularly after its annexation to the city in 1883 . The neighbourhood provided housing for the middle and professional classes of Toronto, seen through the residents' high levels of house ownership, their occupations, with many working downtown as clergymen, lawyers, and doctors, and their religious dominations. ${ }^{19}$ The Annex also boasted larger lots for the most prominent residents, like Timothy Eaton, who moved to the area in 1889, and other elite Torontonians, such as real-estate developer Simeon Henan James, whose home was constructed in the neighbourhood in $1890 .^{20}$

The architecture of the houses in the Annex reflected the values of the neighbourhood's upper classes, and differentiated the area from the overcrowded neighbourhoods in downtown Toronto. Though the neighbourhood also had middle-class occupants, the grand homes of the bourgeoisie dominated the Annex, and influenced its image as a respectable district. In Benvenuto, James's mansion, the hall was the focal point of the home, equipped with a fireplace

\footnotetext{
${ }^{15}$ Whitzman, Suburb, Slum, Urban Village, 64.

16 "Parkdale's Civic Holiday: How Monday Was Celebrated in the Floral Suburb," Globe, August 20, $1879,4$.

${ }^{17}$ Whitzman, Suburb, Slum, Urban Village, 63.

${ }^{18}$ Whitzman, Suburb, Slum, Urban Village, 63, 76.

${ }^{19}$ William Dendy, Lost Toronto (Oxford: Oxford University Press, 1978), 133; City of Toronto Archives, Fonds 92, Item 92, James T. Lemon and Stephen Speisman, "From Farms to Elegant Suburb: 1870s to 1923," 1975, 10.

${ }^{20}$ Dendy, Lost Toronto, 172, 182.
} 
and large enough to act as a general reception area for guests. Drawing and music rooms led off of the central hall, and parts of the home were turned into "nooks," with the intent of providing its inhabitants a place to quietly converse with their guests. ${ }^{21}$ Socializing with other prominent figures was therefore an important pastime of the Annex's wealthy residents and they took an interest in upper class leisure activities focused on the arts, a lifestyle that was not readily accessible for the working classes.

The distinct segregation of lower and upper classes was thus evident in the Annex as it was primarily a suburb for Toronto's affluent families and as a result, it was not an affordable region for lower classes. Toronto's early middle and upper class suburbs consequently functioned as a collection of "fine homes located in graciously planned areas, of green retreats... a happy marriage of city and country," and their residents were drawn to the privacy and apparent vitality that these neighbourhoods offered away from the working class-dominated areas in the downtown region. ${ }^{22}$

Though the relocation of many working class families to suburban areas occurred in the early 1900s, it is important to note that some class diversification existed in more prosperous neighbourhoods during the late 1880s. As a result of the higher costs of homes in the Annex and the generally wealthy demographic in the region, social divisions based on employment were not as evident in the area as they were in Parkdale. Moreover, Parkdale's distance from the city was economically beneficial to the people who settled there, which impacted its class diversity. In an article from 1888, an angry resident wrote to the Globe responding to the controversial topic of Toronto's plan to annex the neighbourhood, and stated that "cheap and comfortable homes and pure water and low taxation" encouraged many residents to move to the area. ${ }^{23}$ In effect, the region was appealing for both the working class and the middle class because of its affordability, and it became a mixed-income community into the 1890s, a feature of other suburban neighbourhoods during the time period such as Yorkville, which has been misinterpreted by some historians as a primarily elite neighbourhood. ${ }^{24}$

Parkdale was also abundant with jobs for both the working class and the middle class. Industries surrounding Parkdale included railways, prisons, and lunatic asylums, which provided

\footnotetext{
${ }^{21}$ Ibid., 183.

${ }^{22}$ Harris, Creeping Conformity, 20.

23 "Against Parkdale Annexation," Globe, January 25, 1888, 4.

${ }^{24}$ Whitzman, Suburb, Slum, Urban Village, 65, 74.
} 
economic opportunities for blue-collar workers, who were able to walk to their places of employment. ${ }^{25}$ However, the proportion of business owners in the municipality remained prominent, particularly from 1890 to 1921, when the percentage of the business class rose from one percent to 17 percent. $^{26}$ Parkdale consequently remained a distinctly middle-class region into the 1900 s, though the "walk-to-workers" also retained a place in the neighbourhood. The integration of classes in suburbs was thus not new, though a dramatic increase of the working class population in the suburbs in the 1900s is evident.

\section{Forceful Integration: Social Development in the 1890s and Onwards}

Greater suburban relocation, occurring in the early 1900s alongside Toronto's annexation of surrounding municipalities, caused middle-class neighbourhoods to become places of residence for a variety of social classes. As the population of the city continued to grow, Toronto looked to expand its borders and consolidate nearby municipalities located on the city's outskirts, which infringed on the segregated class structure found in suburban communities. Besides ongoing annexation, several significant factors contributed to the movement of people out of Toronto's core at the turn of the century. The doubling of inner city rent between 1897 and 1907 influenced working class people to relocate to areas like Parkdale, where it was cheaper to become a homeowner than to pay high rent prices. ${ }^{27}$ Moreover, Toronto's first Housing Commission, established in 1907 , encouraged people to move out of the city to prevent further overcrowding. ${ }^{28}$ Finally, the housing boom that took place between 1906 and 1913 provided lower-class families with opportunities to find inexpensive houses while remaining close to work, and in response to the increase in available housing, home ownership rose, with 77 percent of homeowners living in the suburbs. ${ }^{29}$ Owning a home was particularly important for workers, who placed more importance on owning their home than the middle classes, which indicated that these homeowners were largely from the lower classes. ${ }^{30}$

As a result of urban development, the suburban outskirts of Toronto became increasingly mixed-class. In a study of North Earlscourt, located just outside of the city limits, Richard Harris

\footnotetext{
${ }^{25}$ Whitzman, Suburb, Slum Urban Village, 72-3.

${ }^{26}$ Ibid., 92.

${ }^{27}$ Dennis, "Property and Propriety," 383.

${ }^{28}$ Solomon, Toronto Sprawls, 32.

${ }^{29}$ Whitzman, Suburb, Slum, Urban Village, 92; Choko and Harris, "The Local Culture of Property," 79.

${ }^{30}$ Harris, Creeping Conformity, 27.
} 
argued that the demographic of people moving into the neighbourhood represented the new suburban dwellers across Toronto in the twentieth century, who were primarily the families of blue-collar workers. ${ }^{31}$ According to samples of householders in 1913, 80 percent of employed householders in Toronto were working class residents, with proportions in many suburban districts exceeding 90 percent. $^{32}$ The suburbs became even more blue-collar in character than the city, with only affluent regions like Swansea and Forest Hill preserving a distinctly middle and upper-class presence. ${ }^{33}$

Parkdale was one of the middle class suburbs impacted by the relocation of the working class. The transformation of Parkdale's idealized image was especially notable as residents showed dissatisfaction with the types of people who were moving into their neighbourhoods. In 1913, the area became identified with "the moral danger of single women and men living in apartments and boarding houses" as multiple occupancy increased because of the growing population, an effect which was also evident in the Annex. ${ }^{34}$ While it is clear that suburban residents often reacted negatively to the expanding working class populations in their neighbourhoods, the response is representative of a general attitude towards overcrowding and its adverse effects on communities during the time period. The City Council Housing Commission struggled to ensure accommodations for Torontonians, and placed the necessity of housing over the luxuries of space. Larger middle-class detached homes in Parkdale were criticized as inefficient single-family homes because of their size, which marked a change from the perception of the neighbourhood's homes as pinnacles of "modern fashion and healthfulness" during their construction in the $1880 \mathrm{~s} .{ }^{35}$ The City Council encouraged the re-development of the homes into three-family apartments under rigid regulations, which ensured that slum conditions were avoided, thereby providing more room for residents while preventing a potential spread of shantytowns and run-down boarding houses. ${ }^{36}$ However, through these measures, multiple occupancy increased in Parkdale, which influenced the negative attitudes of the neighbourhood's

\footnotetext{
${ }^{31}$ Harris, "A Working Class Suburb for Immigrants," 321.

${ }^{32}$ Ibid.

${ }^{33}$ Richard Harris, Unplanned Suburbs: Toronto's American Tragedy, 1900 to 1950 (Baltimore: John Hopkins University Press, 1996), 50.

${ }^{34}$ Whitzman, Suburb, Slum, Urban Village, 106; Lemon and Speisman, "Farms to Elegant Suburb," 8.

${ }^{35}$ Whitzman, Suburb, Slum, Urban Village, 106.

${ }^{36}$ Ibid., 123-4.
} 
residents towards the new housing developments since congestion was associated with the 'immoral' downtown city lifestyle.

The impact of the changing demographics in the suburbs was in part manifested in the reorganization of classes through a division of streets by employment and income, and the conflicts that developed concerning the extension of public transit into the neighbourhoods. Certain areas of suburbs were reserved for and promoted to the incoming lower-middle class and working class populations, thus creating areas in neighbourhoods that were divided by occupation and relative wealth. North Parkdale became distinctly working class, while South Parkdale retained a middle class identity. ${ }^{37}$ Undeveloped land near the lake and along Roncesvalles was marketed towards lower classes, who could build their homes in the region and still be a short walking distance from work. ${ }^{38}$ One popular area became known as Galley Avenue, and its occupants included a post office clerk, a checker for the Grand Trunk Railway, and a manager at a downtown factory, though middle-class suburbanites also had homes on Galley. ${ }^{39}$ The segregation of the middle and lower class in Parkdale was not absolute, suggesting that alongside the development of cheap housing for the working class, the neighbourhood also continued to appeal to middle-class commuters, which determined Parkdale's mixed-income status.

The diversification of suburban classes did however have a strong effect on the unofficial partitioning of other neighbourhoods, evident in the Annex. In the early 1900s, the reaction to the increase in working class residents was the relocation of wealthy residents to the side streets, which left "trade on the arterials... with electrified streetcars." 40 The wealthy homeowners moved away from Jarvis Street, leaving the working class near their places of employment, which included stores located on the main streets as well as the railway and other industries north of Dupont and Davenport. ${ }^{41}$ The eastern Yorkville strip, Dupont, and apartments on Bloor became areas that housed the less affluent families, while the richest lived on St. George, Admiral, Bedford, and Spadina, which showed the determination of residents in the Annex to preserve the

\footnotetext{
${ }^{37}$ Ibid., 98.

${ }^{38}$ Ibid., 97.

${ }^{39}$ Whitzman, Suburb, Slum, Urban Village, 97.

${ }^{40}$ Lemon and Speisman, "Farms to Elegant Suburb," 8.

${ }^{41}$ Ibid., 17.
} 
"purity of [their] privacy" and maintain their well-being by creating boundaries between classes. $^{42}$

Moreover, the housing reform movement of the late nineteenth and early twentieth centuries was centralized on the potential proliferation of slum diseases into affluent neighbourhoods, and the deterioration of morality that seemed to spread from the substandard inner city housing, ${ }^{43}$ which might have influenced the upper class residents in the Annex to distance themselves from infringing urbanization. In contrast to Parkdale, the differences in income and occupation were more apparent in the Annex, which created geographical divisions as wealthy families wanted to remain isolated from the industrialized downtown, and maintain an idyllic image of their suburb as a safe space away from city life.

The commuting patterns of suburban residents further marked the social divisions created by the movement and reorganization of various classes in upper class suburbs. By 1890, the electrified streetcar and expanding train lines began to occupy a greater place in urban centres and transported an average of 50,000 to 60,000 people every weekday. ${ }^{44}$ An analysis of expanding public transportation in the early 1900s reveals the unique mobility of "walk-toworkers" and inner city commuters, who occupied houses in the suburbs and used the developing forms of urban travel in different ways. In Parkdale, industries were located close to the neighbourhoods, and allowed industrial workers to walk to their places of employment. Railways and other forms of public transit were then mainly used by the middle-class as they travelled to their downtown jobs, which limited class interactions. ${ }^{45}$

Similar instances of segregated commuting occurred in other suburban neighbourhoods, and in some cases, defined the type of social groups who occupied homes in the region. Methods of public transit were simply more practical for specific classes, seen in Earlscourt in 1911. During this time, Earlscourt residents, who were largely working class and held jobs in the Massey-Harris shops or on King Street West, opposed the construction of the subway system near the neighbourhood, stating that a streetcar would be more beneficial since the fare was affordable for "the poor laborer," and extended Dovercourt and Lansdowne streetcars would cut

\footnotetext{
${ }^{42}$ Ibid.

${ }^{43}$ Sean Purdy, "Industrial Efficiency, Social Order and Moral Purity: Housing Reform Thought in English Canada, 1913-1917," in People, Places and Times: Readings in Canadian Social History, Volume 2: Post-Confederation, ed. Cynthia Comacchio and Elizabeth Jane Errington (Toronto: Nelson, 2006), 107. ${ }^{44}$ Goheen, Victorian Toronto, 72.

${ }^{45}$ Whitzman, Suburb, Slum, Urban Village, 72-3.
} 
back on the time it took to walk to the nearest stop. ${ }^{46}$ The "tubes" on the other hand were intended for "people out on Yonge street way who are building their $\$ 5,000$ houses," according to one disgruntled interviewee, illustrating that certain methods of public transport were more cost-effective for particular social classes. ${ }^{47}$ The extent of servicing provided in neighbourhoods also determined their class diversification. Suburbs like Earslcourt that were not effectively serviced discouraged middle-class residents from moving to these areas, thereby promoting the neighbourhood's status as a working class region. ${ }^{48}$

In the Annex, class variations in commuter use existed since storeowners were housed near their places of employment while middle and upper class commuters travelled daily on streetcar lines to the Central Businesses District. The high proportion of affluent residents using public transportation as a means of commuting made "travelling by streetcar in Toronto... a respectable practice and a not unpleasant experience," indicating that in some regions, it was an upper class method of travel. ${ }^{49}$ Domestic labourers who worked as servants in the homes of the wealthy also used the streetcar, though this group was not heading into the city, but instead travelling in the other direction to regions in southern Toronto where their families lived. ${ }^{50}$ Consequently, social groups who occupied the same suburban neighbourhood often did not share the same forms of public transportation or transit lines, showing the division between the lower and upper classes as they commuted to work. Along with specific geographical localizations of classes that developed as the working class moved out of the city's core, distinct commuter paths revealed the varying degrees of integration and segregation in middle-class suburban communities as their residents adapted to the effects of urbanization.

\section{Conclusion}

The changing social profiles of Toronto's middle and upper class suburbs in the late 1800s and early 1900s produced mixed-income neighbourhoods where social classes experienced divisions based on employment, residential addresses, and methods of commuting. The altered state of the suburb affected its conceptualization as a private and isolated area, which

\footnotetext{
46 “Tube No Benefit to Earlscourt," Globe, December 15, 1911, 1.

${ }^{47}$ Ibid.

${ }^{48}$ Harris, Creeping Conformity, 66.

${ }^{49}$ Lemon and Speisman, 19.

${ }^{50}$ Ibid.
} 
initially existed in contrast to the image of the working class slums in central Toronto. As lower classes migrated to the outskirts of the city, suburbs reacted to class diversification in various ways while developing new characteristics as blue-collar-dominated regions. Not until after WWI did these suburbs regain their middle class statuses, and assume the qualities of suburban living that were associated with the neighbourhoods in the latter half of the twentieth century. 


\section{Bibliography}

“Against Parkdale Annexation.” Globe, January 25, 1888.

Choko Marc, and Richard Harris. "The Local Culture of Property: A Comparative History of Housing Tenure in Montreal and Toronto." Annals of the Association of American Geographers 80, no. 1 (Mar., 1990): 73-95.

City of Toronto Archives. Fonds 92. Item 92. James T. Lemon and Stephen Speisman. "Fro Farms to Elegant Suburbs: 1870s to 1923." 1975.

Dendy, William. Lost Toronto. Oxford: Oxford University Press, 1978.

Dennis, Richard. "Property and Propriety: Jewish Landlords in Early Twentieth-Century Toronto." Transactions of the Institute of British Geographers 22, no. 3 (1997): 377-397.

Goheen, Peter G. Victorian Toronto: 1850 to 1900: Pattern and Process of Growth. Chicago: University of Chicago Printing Department, 1973.

Harris, Richard. “A Working-Class Suburb for Immigrants, Toronto 1909-1913.” Geographical Review 31, no. 3 (Jul., 1991): 318-332.

---. Unplanned Suburbs: Toronto's American Tragedy, 1900 to 1950. Baltimore: John Hopkins University Press, 1996.

---. Creeping Conformity: How Canada Became Suburban, 1900-1960. Toronto: University of Toronto Press, 2004.

McCann, Larry. "Suburbs of Desire: The Suburban Landscape of Canadian Cities, c. 1900 1950." In Changing Suburbs: Foundation, Form and Function, edited by Richard Harris and Peter J. Larkham, 111-145. New York: Routledge, 1999.

"Parkdale's Civic Holiday: How Monday Was Celebrated in the Floral Suburb." Globe, August $20,1879$.

Purdy, Sean. "Industrial Efficiency, Social Order and Moral Purity: Housing Reform Thought in English Canada, 1913-1917." In People, Places and Times: Readings in Canadian Social History, Volume 2: Post-Confederation, edited by Cynthia Comacchio and Elizabeth Jane Errington, 106-122. Toronto: Nelson, 2006.

Solomon, Lawrence. Toronto's Sprawls: A History. Toronto: University of Toronto Press, 2007. "Suburean Corporations." Globe, July 1, 1878.

“Tube No Benefit to Earlscourt." Globe, December 15, 1911.

Whitzman, Carolyn. Suburb, Slum, Urban Village: Transformations in Toronto's Parkdale Neighbourhood, 1875-2002. Vancouver: UBC Press, 2009. 